\title{
Reflexões a cerca das estruturas psíquicas e a prática do Ciberbullying no contexto da escola*
}

\author{
Jefferson Cabral Azevedo** \\ Fabiana Aguiar de Miranda**** \\ Carlos Henrique Medeiros de Souza*****
}

\begin{abstract}
Resumo
Estudo teórico a cerca do Bullying e o Ciberbullying na escola e sua relação com as estruturas psíquicas dos sujeitos envolvidos nesta prática. O objetivo é refletir sobre a potencialização do Bullying na escola por meio dos ambientes virtuais e das redes de computadores, bem como relacionar estas questões com as estruturas psíquicas dos sujeitos envolvidos. Dentro desta perspectiva, pergunta-se: qual é a relação existente a potencialização do Bullying na escola com o aumento de convivência no ciberespaço? Trata-se de uma pesquisa bibliográfica. Constata-se que vivemos na era da informação, de rápidas mudanças nas estruturas sociais e em suas relações. Portanto, há ressignificação dos papéis e a reconstrução dos parâmetros exercidos pela apropriação da convivência diária, não mais fechados e inertes. Poder acessar em tempo real toda sorte de informação de qualquer lugar do mundo, bem como suas principais fontes, representa uma forte mudança de paradigma social e proporciona um futuro cheio de possibilidades e fluidez.
\end{abstract}

* Pesquisa apoiada pela Fundação de Amparo a Pesquisa do Estado do Rio de Janeiro - FAPERJ e CAPES.

** Mestrando no Programa de Cognição e Linguagem, Bolsista Faperj, Centro de Ciências do Homem, Universidade do Estadual Norte Fluminense Darcy Ribeiro-UENF. Professor de Psicologia e Administração na Faculdade Metropolitana São Carlos - FAMESC e Instituto Nossa Senhora da Glória, Campos dos Goytacazes-RJ, Brasil. E-mail: jefpsi@gmail.com

*** Mestranda no Programa de Cognição e Linguagem, Bolsista Faperj, Centro de Ciências do Homem Universidade Estadual do Norte Fluminense Darcy Ribeiro - UENF. Campos dos Goytacazes-RJ. E-mail: fabianaaguiar09@gmail.com **** Professor doutor Associado e coordenador do Mestrado de Cognição e Linguagem, Centro de Ciências do Homem, Universidade Estadual do Norte Fluminense Darcy Ribeiro - UENF. Autor de 6 livros, 26 artigos em diversas revistas nacionais e internacionais, Campos dos Goytacazes- RJ, Brasil. E-mail: chmsouza@gmail.com.

Intercom - RBCC

São Paulo, v.35, n.2, p. 247-265, jul./dez. 2012 
Tais fatos, com facilidade do ciberespaço e nas tendências trazidas por ele, são espraiadas pela virtualização das relações nas Redes Sociais.

Palavras chave: Bullying. Redes Sociais. Psicanálise. Ciberbullying. Estruturas psíquicas.

\section{Reflections about the psychic structures and practice in the school context Ciberbullying}

Abstract

Theoretical study about the bullying and cyberbullying in school and their relationship with the psychic structures of the subjects involved in this practice. The goal is to reflect about Bullying's power at school through virtual environments and computer networks, as well as to relate these issues to the psychic structures of the people involved. It is a Bibliographic research. As result, we can see that we live in the age of information, with fast changes in social structures and their relationships. Therefore, a redefinition of roles, the reconstruction of the ownership exercised by the parameters of daily living, no longer closed and inert. Being able to access real time information of all kinds anywhere in the world, as well as its main sources, represents a strong social paradigm shift and provides a future full of possibilities and fluidity, where the information may of today may be the outdated one from tomorrow, in a short period of time. We can easily observe these facts in cyberspace and in trends brought by it, also done by the virtualization relations in social networks.

Keywords: Bullying. Social Networks. Psychoanalysis. CyberBullying. Psychic structures.

\section{Reflexiones acerca de las estructuras psíquicas y la prácticaen el contexto escolar Ciberbullying}

\section{Resumen}

Estudio teórico sobre la intimidación y el acoso cibernético en la escuela y su relación con las estructuras psíquicas de los sujetos involucrados en esta práctica. Este trabajo se propone una reflexión sobre la potenciación de la intimidación en la escuela, comúnmente llamado de "bullyng", a través de ambientes virtuales y las redes de informáticas, así como las cuestiones relacionadas con las estructuras psíquicas de los sujetos implicados. También, se pretende relacionar estas cuestiones a las estructuras psíquicas de los sujetos implicados. Dentro esta perspectiva, apuntamos la pregunta que guía este estudio, “¿Cuál es la relación existente entre la potenciación de la intimidación en la escuela, y el aumento de la convivencia en el ciberespacio?”. Esta investigación tuvo como objetivo desarrollar un estudio teórico sobre el Bullying y el Ciberbullying en la escuela, y su relación con las estructuras psíquicas de los sujetos involucrados en esta práctica. Esta investigación tuvo carácter exploratorio, con revisión de la literatura. Con esta investigación podemos afirmar que vivimos una era de 
información, de rápidos cambios en las estructuras sociales y sus relaciones. Por lo tanto, debemos reflexionar sobra la necesidad de una redefinición de los roles, y la reconstrucción de la propiedad ejercida por los parámetros de la vida diaria, ya no cerrados e inertes. Ser capaz de acceder información de todo tipo en tiempo real, en cualquier parte del mundo, así como a sus fuentes principales, representa un fuerte cambio de paradigma social y ofrece un futuro lleno de posibilidades y fluidez, en donde la información ahora puede ser obsoleta mañana, en un período de tiempo corto. Podemos observar estos hechos con facilidad en el ciberespacio, los que son también diseminados por la creciente forma virtual de las en las redes sociales.

Palabras clave: La intimidación. Las redes socialespsicoanálisis. Ciberbullying. Estructuras psíquicas.

\section{Introdução}

odo processo institucional, inclusive o escolar, tem relação
com a mudança nas relações de trabalho e os avanços
científicos. Consequentemente, as identidades oriundas destes choques entre concepções proporcionam novos paradigmas relativos à fluidez de comportamento e ao referencial para a estruturação psíquica.

Vivemos na era da informação, de rápidas mudanças nas estruturas sociais e em suas relações. Não é, portanto, uma simples questão de ponto de vista, é uma ressignificação dos papéis, ou melhor, a reconstrução dos parâmetros exercidos pela apropriação da convivência diária, não mais fechados e inertes.

Poder acessar em tempo real toda sorte de informações de qualquer lugar do mundo, bem como suas principais fontes, representa uma forte mudança de paradigma social e proporciona um futuro cheio de possibilidades e fluidez, onde a informação do hoje pode ser a ultrapassada de amanhã, num curto espaço de tempo.

Podemos observar tais fatos com facilidade no ciberespaço e nas tendências trazidas por ele também espraiadas pela virtualização das relações nas Redes Sociais.

Neste âmbito paradigmático e crível, às vezes nos assolamos com demonstrações de comportamentos que chocam e impressionam um grande número de pessoas, como assassinatos em massa 
em instituições escolares, principalmente nos Estados Unidos, na Europa e, agora, também se apresenta no Brasil. Entretanto, quem podemos culpar? Estipular culpa sobre as relações familiares? Sobre os preconceitos e abusos físicos e psíquicos originados no meio escolar? Muitas pessoas passaram por estas situações de frustrações, constrangimentos, agressões físicas e psicológicas e nem por isso tiveram comportamentos que demonstrassem violência ou extermínio. Podemos pensar em comportamentos agressivos e violentos contra nossos familiares, chefes, colegas de trabalho e escola, mas chegar a praticá-los é outra instância. $\mathrm{O}$ ato de pensar e agir passa pelo processo de censura, que define o comportamento social.

Dentro destas perspectivas destacamos a necessidade de uma reflexão a cerca da potencialização do Bullying na escola por meio dos ambientes virtuais e das redes de computadores. A questão principal desta pesquisa foi: "Qual é a relação existente a potencialização do Bullying na escola com o aumento de convivência no ciberespaço?". Ressaltamos que o objetivo deste estudo foi desenvolver uma pesquisa teórica a cerca do Bullying e o Ciberbullying na escola e sua relação com as estruturas psíquicas dos sujeitos envolvidos nesta prática. Tratou-se de uma pesquisa exploratória com procedimento de revisão bibliográfica.

\section{Identidade, Poder e Redes Sociais}

No quesito redes sociais, de acordo com a perspectiva de Castells (2005, p.49),

(...) redes são estruturas abertas capazes de expandir de forma ilimitada, integrando novos nós desde que consigam comunicar-se dentro da rede, ou seja, desde que compartilhem os mesmos códigos de Comunicação (por exemplo, valores ou objetivos de desempenho). Uma estrutura social com base em redes é um sistema aberto, altamente dinâmico, suscetível de inovação sem ameaças ao seu equilíbrio.

Essas relações são marcadas pelo poder, ressaltado por Foucault (1999), em "Microfísica do Poder", em seu aspecto imperativo sobre os corpos, físicos ou imaginários, sob a tutela da disciplina. 
A disciplina que Foucault mostra é, pois, uma política do detalhe e, desta forma, desenha uma Microfísica do Poder que vem evoluindo em técnicas cada vez mais sutis, sofisticadas, com aparente inocência, tomando o corpo social em sua quase totalidade. É assim no contexto disciplinar dos regulamentos minuciosos, do olhar das inspeções e no controle sobre o corpo que toma forma nas escolas, nas redes sociais e outros lugares comuns.

É preciso agora esmiuçar esta tecnologia disciplinar em seus diferentes componentes para estudá-la, bem como sua inserção na escola e na vida cotidiana.

A violência, seja ela psíquica ou física, é a expressão maior do exercício do poder, é a domesticação dos corpos e das mentes, submetendo o indivíduo a uma relação de sujeitado.

A introjeção nos corpos desta disciplina dos espaços ganha prolongamento social expresso nas ações dos corpos em sua vida cotidiana e produz as "arrumações" de todos os espaços. A subordinação à vigilância contínua é reproduzida pela coerção interna do indivíduo, isto é, o próprio indivíduo coloca-se no espaço possível de vigilância, que é o lugar da submissão e reproduz esta distribuição sem que necessariamente o vigiem.

Segundo Mason (2008), o ciberespaço ganhou notoriedade e tornou-se também lugar de violência. No entanto, a popularidade da Internet e de outras tecnologias, sobretudo as de Comunicação, apoiadas na repercussão das redes sociais inclusive dentro das salas de aula, fez surgir uma nova forma de agressão e ameaça entre alunos: o CyberBullying. $\mathrm{O}$ uso dos aparelhos eletrônicos para ameaçar outros estudantes torna-se a cada dia problema mais sério nas escolas.

Para Li (2006), há um número significativo de jovens que já sofreram este tipo de violência pela rápida propagação que as redes sociais oferecem.

Na opinião de Nogueira (2003), em função das fronteiras da violência se tornarem maleáveis, frágeis e difíceis de serem definidas é que muitas vezes a mesma se confunde, se interpenetra, se inter-relaciona com agressão e indisciplina na esfera escolar, e os casos de violência entre pares acabam naturalizados. Conforme a autora salienta, “(...) a grande maioria dos profissionais 
da Educação não sabe tratar e distinguir os alunos agressivos dos indisciplinados e violentos, arriscando pseudodiagnósticos" (p.93) e isso, em si, já contribui para a dissimulação do próprio fenômeno, dificultando sua delimitação e estudo.

Contemporaneamente, convive-se com um agravante considerado uma evolução na manifestação do Bullying, o chamado Cyberbullyng. Este comportamento envolve o uso da informação e das tecnologias digitais atuais, como e-mails, mensagens para celulares, mensagens de texto instantâneas, MSN, ICQ, web sites pessoais, comunidades virtuais, sites de relacionamento, dentre outros, como meio de apoio deliberado para a propagação de comportamento hostil com o objetivo repetido de injuriar, caluniar e prejudicar alguém (BELSEY, 2009).

De acordo com Maia (2007, p.4),

A modernidade líquida, apresentada por Bauman (2005), reflete sobre a decadência de instituições sociais que até então se prestavam como referência para a construção da sociedade provoca o que Stuart Hall (2006) intitula de crise da identidade. Paisagens culturais de classe, gênero e etnia que no passado forneciam os alicerces para a localização dos indivíduos, estão sendo fragmentadas.

A escola e a família não são os únicos referenciais para a formação das identidades e estruturação psíquica, o não lugar proporcionado pelas novas tecnologias adentrou tais ambientes restritos e concorre para estabelecer novos valores e parâmetros de convivência, de relações e propagação de poder e formação de identidades, sejam patológicas ou não.

O processo de formação de identidades nas redes perpassa vários aspectos interessantes e ao mesmo tempo trágicos, pois, segundo Freud (1969), a formação da personalidade se dá através e pelo Outro. Entretanto, quem é este outro dentro de um mundo tecnologicamente virtual, onde as relações são efêmeras e transitórias? Por vezes, as Redes Sociais funcionam como um grande grupo que exerce influência sobre os comportamentos dos componentes e subjuga a identidade individual. Para Le Bon (1969), "os dotes particulares dos indivíduos se apagam num grupo e, dessa maneira, sua distintividade se desvanece". 
Segundo Freud (1969, p.36), em "Psicologia das Massas e análise do Eu", existem dois fatores importantes:

O primeiro é que o indivíduo que faz parte de um grupo adquire, unicamente por considerações numéricas, um sentimento de poder invencível que lhe permite render-se a instintos que, estivesse ele sozinho, teria compulsoriamente mantido sob coerção. Ficará ele ainda menos disposto a controlar-se pela consideração de que, sendo um grupo anônimo e, por conseqüência, irresponsável, o sentimento de responsabilidade, que sempre controla os indivíduos, desaparece inteiramente.

Outro fator importante é a relação de contágio pelo qual o comportamento individual é diretamente influenciado como no "efeito manada": o discernimento e a vontade própria desaparecem por completo passando, assim, a assumir uma identidade grupal.

\section{Bullying: Violência no âmbito escolar}

As diferentes manifestações de violência urbana vêm adquirindo cada vez mais importância e dramaticidade na sociedade brasileira, especialmente a partir da década de oitenta. Muitas são as suas expressões, os sujeitos envolvidos e as consequências. $\mathrm{O}$ frequente envolvimento da população infantil e juvenil com esta realidade ocupa, de maneira crescente, as páginas da imprensa falada e escrita. Tal problema tem muitas implicações do ponto de vista da prática educativa, e suas diferentes manifestações têm preocupado de forma especial pais e educadores.

De acordo com tal perspectiva, é possível destacarmos alguns aspectos que têm caracterizado nossa sociedade nos últimos anos: o intenso processo de urbanização, as migrações internas com suas consequências de desenraizamento social, cultural, afetivo e religioso, a acelerada industrialização, o impacto das políticas neoliberais, a expansão das telecomunicações, a cultura do consumo, a enorme concentração de renda, a crise ética, o aumento da exclusão e do desemprego.

Para muitas pessoas, o aumento da violência está relacionado ao número de jovens e crianças que vivem pelas ruas das grandes cidades. Assim, manifestações de violência estariam relacionadas 
às classes populares. Contudo, considerar a pobreza e a miséria como as únicas causas da violência é, no mínimo, uma análise reducionista e simplista da questão. Jovens filhos de famílias favorecidas economicamente também se envolvem em atos ilícitos e em situações de violência e agressão deliberadas.

De acordo com Sposito (1994), não é de hoje que profissionais da educação, alunos e pais vêm se surpreendendo com problemas de violência entre jovens alunos de classe média. Apesar das preocupações generalizadas, os olhares dos pesquisadores têm se voltado majoritariamente para as manifestações de violência entre jovens das classes populares.

A discussão sobre violência é importante, porque é um fenômeno que se desdobra no ambiente da instituição escolar.

Mediante os estudos desenvolvidos por Sposito (1994) a análise do fenômeno da violência escolar adentra os âmbitos sociológicos e psicológicos. E, assim, vemo-nos diante de uma série de dificuldades para contemplar e processar, não apenas o fenômeno, pela sua complexidade, mas, principalmente, porque nos faz refletir sobre nós mesmos, sobre nossos pensamentos e nossos paradigmas em relação à construção de uma naturalização da violência na sociedade pós-modernas.

Assim segundo o autor, podemos afirmar que a violência no meio escolar tanto decorre da situação de violência social que atinge a rotina dos estabelecimentos de ensino ultrapassando suas fronteiras geográficas, como pode expressar modalidades de ação que nascem no ambiente pedagógico e de seu exercício de reprodutor e produtor de violência. Tal situação, como por ebulição, ultrapassa as fronteiras geográficas e a noção de tempo e espaço e a violência atinge, então, o não lugar definido, segundo Souza (2005), como lugar do virtual, abrigando uma série de complexos fenômenos, dentre os quais o Bullying escolar.

$\mathrm{Na}$ visão de Fante (2002), o Bullying escolar, ou violência entre pares, é um fenômeno tão antigo quanto prejudicial, que pode deixar marcas profundas na vida de um sujeito. Apesar dos educadores terem consciência da problemática existente entre agressor e vítima, poucos esforços foram despendidos para o seu estudo sistemático até princípios dos anos setenta. 
Segundo a autora, durante vários anos essa intenção ficou restrita apenas à Escandinávia. Na década de setenta, surgiu na Suécia um grande interesse de toda a sociedade pelos problemas desencadeados pelo fenômeno. Na Noruega, o fenômeno Mobbing, como é denominado nesse país, durante muitos anos foi motivo de preocupação dos meios de Comunicação, de professores e de pais, porém sem que as autoridades educativas se comprometessem de forma oficial.

Para Orte (1996), o Bullying escolar se apresenta como um mal-estar que se observa desde a perspectiva oculta, desde o desconhecimento, desde a indiferença. Ou, inclusive, desde a ausência de valorização de si mesmo, de sua própria existência e das consequências que o mesmo pode ter e tem no desenvolvimento social, emocional e intelectual dos menores que sofrem ou padecem por este novo e velho fenômeno. Ainda de acordo com a autora, pode-se considerar o Bullying como um fenômeno novo porque deve ser objeto de investigação, uma vez que se apresenta na desigualdade entre iguais, resultando num processo em que os iguais projetam seu mau caráter de forma oculta dentro de um mesmo contexto. Por outro lado, considera-se o fenômeno como um fato velho, por se tratar de uma forma de violência que ocorre nos centros educativos há muito tempo, em que os "valentões" oprimem e ameaçam suas vítimas por motivos banais, querendo impor sua autoridade.

Segundo Fante (2002), o Bullying não se trata de um episódio esporádico ou de brincadeiras próprias de crianças; é um fenômeno violento que se dá em todas as escolas, e que propicia uma vida de sofrimento para uns e de conformismo para outros. Para a autora, os danos físicos, morais e materiais, os insultos, os apelidos cruéis e as gozações que magoam profundamente, as ameaças, as acusações injustas, a atuação de grupos que hostilizam a vida de muitos alunos levando-os à exclusão, tudo isso são algumas das condutas observadas em relação ao Bullying escolar. Algumas informações e relatos extraídos de jornais ou de estudos realizados podem anunciar a extensão e magnitude do problema.

Intercom - RBCC 


\section{Virtualização das Relações}

O termo sociedade em rede diz respeito a uma composição social estruturada no espaço simbólico do ambiente virtual ou ciberespaço, a partir de circuitos de informação derivados do avanço das tecnologias de base microeletrônica que deram origem à Internet, a espinha dorsal da Comunicação global mediada por computadores no início dos anos de 1990. A Internet é mais que uma simples tecnologia, é o meio de Comunicação que institui a infraestrutura organizativa das sociedades em vigor. A Internet é o coração de um novo paradigma sociotécnico que constitui, na realidade, a base material de nossas vidas e de nossas formas de relação, de trabalho e de Comunicação. O que a Internet faz é processar a virtualidade e transformá-la em nossa realidade, constituindo a sociedade em rede, que é a sociedade em que vivemos.

$\mathrm{Na}$ virtualização das relações, implicitamente podemos observar o Poder da Visibilidade, a busca pela visibilidade dentro das redes pode trazer consigo comportamentos que não são admitidos no mundo "Real", onde as relações são marcadas por normas e regras. Tais normas e regras não são estabelecidas nas redes e são, assim, subjetivas, apresentando pouca capacidade ou força de gerar senso crítico. Neste âmbito, podemos presenciar a utilização de artifícios para conseguir a visibilidade passando por cima da Ética e da Moralidade.

Turkle (2006 apud SOUZA, p.6) destaca, em "Comunicação Linguagem e Identidade”, o conceito desenvolvido por:

Na história da construção da identidade na cultura da simulação, as experiências na Internet ocupam um lugar de destaque, mas essas experiências só podem ser entendidas como parte de um contexto cultural mais vasto. Esse contexto é a história da erosão das fronteiras entre o real e o virtual, o animado e o inanimado, o eu unitário e o eu múltiplo, que está a ocorrer tanto nos domínios da investigação científica de ponta como nos padrões da vida quotidiana (TURKLE, 1997, p.12).

Para Castells (2005), as redes são constituídas de pessoas, pois elas é que são capazes de conectar e criar vínculos entre si, e isto não ocorre do mesmo modo com as instituições. 
Segundo Souza (2005), estamos diante de várias mudanças na sociedade moderna, trazidas pela cibercultura. Inferimos que estamos diante de uma nova forma de produção social do espaço, na qual o tempo-real instantâneo é um tempo sem tempo e o novo dia-a-dia é destituído de espaço e matéria.

Nesta reflexão é possível constatar que este dinamismo de tudo que está contido no ciberespaço cria novas ambiências, hábitos e comportamentos - fatos estes que não há como ignorar ou simplesmente evitar. Souza (2003) ainda nos alerta que as tecnologias se sucedem uma a uma e o novo de hoje é fruto de um amadurecimento, de uma evolução que se desenvolve progressivamente, ou seja, o novo de hoje é o avançado do ontem e o ultrapassado do amanhã.

A imagem-fluxo, a presentificação, a realidade virtual e as diversas possibilidades de Comunicação no ciberespaço sugerem um novo ambiente: as cidades digitais. A realidade virtual que se apresenta no ciberespaço não é somente fruto de contemplação sensorial das imagens e troca de informações, mas uma forma objetiva de ser da nova materialidade do arranjo social em redes de Comunicação.

\section{O CyberBullying}

Com a chegada e o crescimento acelerado da tecnologia, surgiu uma nova forma de intimidação, que ultrapassou o aspecto físico presencial - o CyberBullying - uma forma dissimulada de Bullying, em que as agressões são virtuais. É caracterizado por agressões, insultos, difamações, maus tratos intencionais, contra um indivíduo ou mais, utilizando, para isso, os meios tecnológicos. Avilés (2009) o define como uma forma de "assédio entre iguais através do celular e da Internet", em que as agressões são feitas "através das novas tecnologias de informação e Comunicação, em espaços virtuais".

(...) identifica o Bullying em três grandes tipos. Segundo a autora, baseando-se no estudo teórico de produções na área, o que se chama por Bullying é dividido da seguinte maneira: diretos e físicos, que inclui agressões físicas, roubar ou estragar objetos dos colegas, extorsão de dinheiro, forçar com-

Intercom - RBCC 
portamentos sexuais, obrigar a realização de atividades servis, ou a ameaça desses itens; diretos e verbais, que incluem insultar, apelidar, "tirar sarro", fazer comentários racistas ou que digam respeito a qualquer diferença no outro; e indiretos que incluem a exclusão sistemática de uma pessoa, realização de fofocas e boatos, ameaçar de exclusão do grupo com o objetivo de obter algum favorecimento, ou, de forma geral, manipular a vida social do colega (MARTINS, 2005, p.17).

Lopes Neto (2005) enfatiza a utilização das novas tecnologias para um novo modo de intimidação, o CyberBullying, que na verdade é a utilização da tecnologia da Comunicação para a realização desta violência.

O CyberBullying apresenta particularidades que o diferem de agressões presenciais e diretas e o tornam um fenômeno que nos parece ainda mais cruel, pois, diferentemente do assédio presencial, não há necessidade das agressões se repetirem. $\mathrm{O}$ assédio se abre a mais pessoas rapidamente devido à velocidade de propagação de informações nos meios virtuais, invadindo os âmbitos de privacidade e segurança. Mason (2008) aponta que, a cada dez adolescentes, oito usam a Internet em casa, o que significa que o praticante do CyberBullying pode agredir sua vítima quando não está na escola ou nas proximidades dela e, portanto, o lar pode não ser mais um refúgio seguro e os agressores não precisam mais de um local físico para molestar a vítima. Pode-se dizer que o Bullying digitalizado é extensão do pátio da escola - as agressões podem continuar por longas horas depois do horário escolar. No entanto, para algumas vítimas, a Internet pode ser um lugar de vingança, onde podem, também elas, ameaçar e intimidar os outros para compensar o fato de terem sido agredidos pessoalmente. E a Internet abrange, ainda, um número muito maior de espectadores que podem fazer um pré-julgamento dos envolvidos.

Os autores intimidam suas vítimas por meio de dois principais instrumentos: computadores e telefones celulares. Por meio da Internet, agressores podem enviar mensagens abusivas, obscenas ou difamadoras via e-mail, em sites de relacionamento (como Orkut, Facebook, Twitter) ou utilizando-se de programas de mensagens instantâneas (como MSN e Google Talk). De acordo com Mason, há também a promoção de sites pessoais ou blogs que disseminam 
conteúdo difamatório. Mensagens agressivas e fotos podem também ser enviadas através de telefone celular. Santomauro (2010) afirma em sua pesquisa, com fonte da Fundação Telefônica do estado de São Paulo, que, em 2008, 68\% dos adolescentes ficam online pelo menos uma hora por dia durante a semana; outro levantamento recente, feito pela ComScore, revela que os jovens com mais de 15 anos acessam os blogs e as redes sociais 46,7 vezes ao mês. Os dados demonstram que os adolescentes, quando estão em casa, passam muito tempo conectados à rede mundial de computadores, a maior parte se relacionando com outros sujeitos a partir de sites e programas de conversas instantâneas (ZAMBONI; BOZZA, 2010).

Em tempos atuais, é comum o jovem possuir um ou mais telefones celulares e ter acesso ilimitado e sem controle à Internet. Portanto, indivíduos com intenções perniciosas encontram grande facilidade de ameaçar ou insultar seus alvos. E, mesmo que lhes falte a intenção maledicente, há ainda uma tendência de "tornar normal" ou naturalizar essas formas de abuso, uma espécie de "desengajamento moral" em que meninos e meninas, heterônomos, acabam por justificar suas ações com "todo mundo faz" ou pela "moda" ou, portanto, para "pertencer" à classe daqueles que estão "antenados" nos blogs, ou quaisquer outras formas de veiculação de suas intimidades ou de outrem.

O Bullying digitalizado é uma manifestação violenta grave que não pode ser tolerada, precisa ser pesquisado e divulgado, já que pode ocorrer de maneira anônima no "mundo virtual" de crianças e jovens. O praticante do cyberBullying esconde-se, facilmente, sob uma identidade alternativa, virtual, fazendo com que se sinta seguro para praticar a violência sem sofrer reprimendas.

Segundo Prados (2006), a Internet, de certa forma, desperta em alguns jovens o sentimento de que não existem normas, regras e nem moralidade que regule a vida na rede, de maneira que pode ser usada para o bem ou para o mal. Além de distanciar a vítima do agressor (seguro por não estar cara-a-cara com o alvo), ainda traz consequências terríveis a quem sofre as agressões. $\mathrm{O}$ mesmo autor diz que, embora se pareça com as consequências do Bullying, os danos causados às vitimas de CyberBullying são ainda 
maiores, pois a Internet garante o anonimato daquele que agride, o que dificulta os mecanismos de respostas e proteção a esse tipo de humilhações.

\section{Estruturação psíquica e problemas psicológicos associados ao Bullying/CyberBullying}

O Bullying não é um fenômeno novo e, por isto mesmo, apresenta aspectos e fatores econômicos, políticos e sociais. Dentro de uma perspectiva psicológica e, mais apropriadamente, da psicanálise, o Bullying remonta às bases da formação da personalidade e sua relação com os fatores ambientais; aproxima-se do conceito de preconceito e emite reflexos dos fatores culturais e históricos para sua execução e propagação. Entretanto, há critérios bastante singulares entre os aspectos de estrutura psíquica dos agressores e os transtornos oriundos desta relação no psiquismo das vítimas.

A violência não é um fenômeno moderno, mas que ganha conotações bastante avassaladoras com os avanços tecnológicos e, também, pela crescente urbanização da sociedade que diminui espaços a exarceba comportamentos que hoje podemos denominar de politicamente incorretos. Os comportamentos agressivos originados de transtornos causados por agressões têm aumentado as reações violentas, como ataques armados a escolas e locais públicos e o aumento circunstancial de suicídios.

Desse modo, podemos nos basear no desenvolvimento psicossocial descrito e explicado por Freud (1969).

Por meio das análises realizadas por Rouanet (1998, p.44), das obras freudianas, destacamos que

O desenvolvimento psicossexual culmina exatamente na constituição do superego quando, por meio da resolução do Complexo de Édipo, as leis, as normas e o sistema de valores vigentes, encarnados na figura paterna, são introjetados pelo sujeito. Deste modo, quando ele chega à fase adulta, tem a sociedade em si mesmo e apresenta-se adequadamente susceptível à obediência à autoridade que se encontra mascarada neste momento histórico em que a ideologia confunde-se com a própria realidade. Exatamente por isso, hoje, a crítica à ideologia constitui-se a partir da crítica à realidade. 
Dentro deste processo, a ideologia e a socialização são internalizadas também pelo agressor e este, muitas vezes, desenvolve uma profunda alienação em relação ao próprio processo, colocando-se como vítima quando sofre a reações de seus atos.

Segundo a psicanálise, o agressor é, antes de tudo, um sádico. Lembremos que o sadismo, para a psicanálise, consiste no exercício da violência ou do poder sobre a outra pessoa como objeto.

Para compreender melhor tal processo, é necessário, antes, entender a perspectiva das relações de desejos dentro da teoria freudiana.

O desejo, segundo Lacan (1999), não se refere ao mundo biológico (baseado na satisfação das necessidades fisiológicas), mas é, por assim dizer, desnaturalizado e engajado no mundo simbólico e, porventura, inconsciente.

Segundo Freud (1969), o desejo surge a partir do desejo do Outro e, para tal, é necessário internalizá-lo, suprimi-lo, assimilando-o. Para Garcia-Roza (2003),

O desejo é uma ação "negratriz", pois tem por objetivo a destruição ou transformação do objeto para que o desejo possa ser satisfeito. No lugar da realidade objetiva (destruída ou transformada, surge uma realidade subjetiva pela assimilação ou interiorização do objeto (GARCIA-ROZA, 2003, p.56).

Assim, pode-se dizer que o agressor se identifica com o agredido e necessita da vítima para que possa ser reconhecido. Neste sentido, o agressor, segundo Garcia-Roza (2003), "só pode afirmar o seu desejo na medida em que nega o desejo do outro e tenta impor a esse outro o seu próprio desejo". Ao negar o objeto de desejo (o outro), assimilando-o, o sujeito afirma-se como superior, mas permanece totalmente dependente deste, ou seja, o agressor é um dependente da vitima para se afirmar ou sentir-se seguro. $\mathrm{O}$ agressor é, antes de tudo, um inseguro.

A vítima, exposta a situações de humilhações e agressões psíquicas ou físicas, pode adquirir vários transtornos, como baixa autoestima, depressão, pensamento e ações suicidas e violência explícita ao agressor ou ao meio social.

\section{Considerações finais}

Por meio do controle dos corpos, pela disciplina, se estabelecem as técnicas de submissão seja dos agressores ou da submissão 
das vitimas, ou ainda, das perspectivas dos espectadores. E um dos maiores controles se dá na concepção e nas expectativas oriundas dos papeis sociais assumidos por cada sujeito em relação ao seu próprio papel, uma grande rede social baseada nas relações de poder. Para Foucalt (1999, p.36)

Estas técnicas disciplinares (Espaço/Tempo/Vigilância e Saber) são a garantia para o adestramento, para a subordinação, acrescidos de outras tantas técnicas sutis de aprisionamento dos corpos. A escola, assim, organiza-se de forma a reproduzir a submissão e produzir os corpos dóceis que culmina na subordinação social, na dominação, na alienação e aceitação.

De acordo com Castells (2005), não devemos compreender estes processos apenas como oriundos da modernidade científica. Anteriormente, a sociedade também se estruturava em redes, porém, com a tecnologia da informação, este processo ganhou penetrabilidade, adentrando todos os setores da vida social, inclusive da generalização da violência nas Redes sociais digitais.

É importante tentarmos compreender que os aspectos de estruturação de um sujeito não são necessariamente relativos e unicamente direcionados aos processos intrapsíquicos, são aspectos multicausais e, por isso mesmo, complexos. Portanto, não se pode reduzir os processos sociais e psicológicos a um simples sistema baseado em causa e efeito. Primeiramente, porque é complexo definir o que é causa e o que é efeito. Depois, por nos depararmos com o problema relativo à repetitividade, que defini o Bullying, mas não o cyberBullying por ser atemporal e não respeitar os espaços geográficos escolares. Os processos devem ser vistos como um todo, como uma Gestalt, e não isolar uma parte artificialmente. Não podemos isolar processos cognitivos, motivacionais, emocionais e sociais e outras para caracterizarmos isoladamente seus efeitos sobre o comportamento humano, pois estes processos são utilizados concomitantemente, ou seja, o comportamento humano é mais que a soma destes processos, é a relação existente entre eles.

Mediante a esta análise, é possível concluir que este mundo novo trazido pelas novas tecnologias está cada vez mais presente no cotidiano social. E é inegável que esta revolução cibernética-tecnológica afeta os mais variados aspectos da sociedade através da inserção de novos contextos virtuais, como as Redes Sociais digitais. 
E o uso dessas Redes Sociais digitais impõe, muitas vezes, a atemporalidade e uma propagação extremamente rápida da violência virtual que também traz impactos irreparáveis ao psiquismo e à vida social das vítimas de CyberBullying.

\section{Referências}

AVILÉS, J. M. CyberBullying: Diferencias entre el alumnado de secundaria. Boletin de Psicologia, n.96, p.79-96, 2009.

BELSEY, B. 2005. What are the forms that cyberBullying might take? Disponível em: http://www.cyberBullying.ca. Acesso em: 25 mar.2009.

CASTELLS, Manuel. A sociedade em rede - a era da informação: economia, sociedade e

Cultura. 6. ed. São Paulo: Paz e Terra, 2005.

FANTE, C. A. Z. Bullying escolar. In: Violência nas escolas. Jornal Diretor Udemo, ano v, n.2, mar. 2002.

FOUCAULT, M. Microfísica do Poder. Rio de Janeiro: Graal, 1999.

FREUD, S. Totem e Tabu e outros trabalhos. In: E.S.B., v.12,. Rio de Janeiro, Imago, 1969.

. (1914) Historia do movimento psicanalítico. E.S.B., v. XXI. Rio de Janeiro: Imago, 1996.

. (1921) Psicologia das Massas e análise do Eu. E.S.B., v. XXI. Rio de Janeiro: Imago, 1996. Imago, 1996.

. (1917 [1915]) Luto e melancolia. E.S.B., v. XXI. Rio de Janeiro:

. (1927) O futuro de uma ilusão. E.S.B., v. XXI. Rio de Janeiro: Imago, 1996.

. (1930 [1929]) O mal-estar na civilização. E.S.B., v. XXI. Rio de Janeiro, Imago, 1996.

GARCIA-ROZA, L. A. Freud e o inconsciente. Rio de Janeiro: Zahar, 2003.

. Introdução a metapsicologia freudiana. Rio de Janeiro: Jorge

Zahar Editor, 2003.

Intercom - RBCC

São Paulo, v.35, n.2, p. 247-265, jul./dez. 2012 
LACAN, J. Seminário: as formações do inconsciente. Rio de Janeiro: Zahar, 1999.

LI, Q. New bottle but ould wine: A research of ciberbulluing in schoools. Computers in Human Behavior 23, n.4, p.1777 - 1791, 2007.

LEVY, P. Cibercultura. São Paulo: Ed. 34, 1999.

LOPES, A. A. Bullying: Comportamento agressivo entre estudantes. Jornal de Pediatria, v.c81, n.5, p.164-172, 2005.

MARTINS, M. J. D. O problema da violência escolar: uma clarificação e diferenciação de vários conceitos relacionados. Revista Portuguesa de Educação, v. 18, n. 1, 2005.

MAIA, A. S. C. Telenovela Projeção, identidade e identificação na modernidade líquida. Universidade Federal de Juiz de Fora. Minas Gerais, ago. 2007. Disponível em: < http://www.compos.org.br/files/24ecompos09_AlineMaia.pdf>. Acesso em: 15 maio 2010.

MASON, K. L. CyberBullying (intimidação psicológica com a ajuda da tecnologia): Avaliação preliminar no ambiente escolar. Psychology in the Schools, Universidade Estadual de Cleveland, v.45, n.4, 2008.

NOGUEIRA, R. M. C. D. P. A. Escola e violência: análise de Dissertações e Teses sobre o tema produzidas na área de Educação, no período de 1990 a 2000. Dissertação (Mestrado em Educação) - Pontifícia Universidade Católica de São Paulo, PUC, São Paulo- SP, 2003.

ORTE, C. S. El Bullying versus el respeto a los derechos de los menores en la educación. La escuela como espacio de disocialización. Revista Interuniversitaria de Pedagogia Social, Universitat de Les Illes Balears, n.14, 1996.

PRADOS, M. A. H. Menores y riesgos en la Red - Un dilema para los padres. III Congresso online - Observatorio para la Cibersociedad, 2006.

ROUANET, S. P. Teoria, crítica e psicanálise. Rio de Janeiro: Tempo Brasileiro, 1998.

SANTOMAURO, Beatriz. Violência virtual, Revista Nova Escola, São Paulo, jun./jul/2010.

SOUZA, C. H. M.; COSTA, M. A. B. Abordagens antropológicas do ciberespaço e da cibercultura. In: Revista Tempo Brasileiro, Rio de Janeiro, n.163, p.85-94, out./dez. 2005. 
SOUZA, C. H. M. Comunicação, educação e novas tecnologias. Campos dos Goytacazes, ed. FAFIC/Grafimax, 2003.

Comunicação, linguagem e identidade. Universidade Estadual do Norte Fluminense - UENF, set. 2006. Disponível em: < http://www.intercom.org. br/papers/nacionais/2006/resumos/R0240-2.pdf>. Acesso em: 25 maio 2010.

SOUZA, J. (Org.). A invisibilidade da desigualdade brasileira. Belo Horizonte: UFMG, 2006.

SPOSITO, M. P. Sociabilidade juvenil e a rua: novos conflitos e a ação coletiva na cidade. Tempo Social, Revista de Sociologia da USP, São Paulo, n.5, p.1-2, 1994.

TURKLE, S. A vida no ecrã - A identidade na era da Internet. Lisboa, Relógio D'água, 1997.

ZAMBONI, E., BOZZA, T. C. L. Os jovens e a cultura contemporânea. Pesquisa de iniciação cientifica em desenvolvimento na Faculdade de Educação da UNICAMP, 2010. 


\section{História da Imprensa}

Edição atualizada da obra clássica de Nelson Werneck Sodré na qual o autor faz um profundo estudo sobre a imprensa e traça um painel denso e complexo da imprensa que começou a circular, no país, a partir da chegada da Corte Portuguesa, em 1808.

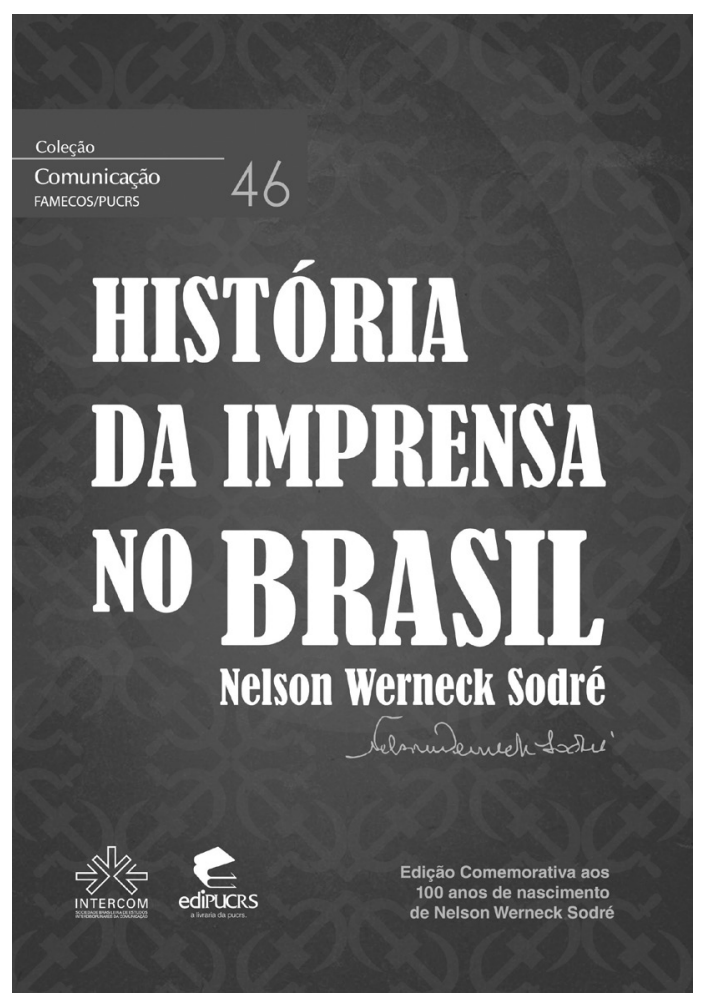

FAÇA SEU PEDIDO pelo telefone (0xx11) 2574-8477, e-mail: intercom@usp.br ou acesse a Livraria Virtual da Intercom: http://www.intercom.org.br 